\title{
Measurement report: Online measurement of gas-phase nitrated phenols utilizing a CI-LToF-MS: primary sources and secondary formation
}

\author{
Kai Song ${ }^{1,2}$, Song Guo ${ }^{1,2}$, Haichao Wang ${ }^{3}$, Ying Yu ${ }^{1}$, Hui Wang ${ }^{1}$, Rongzhi Tang ${ }^{1}$, Shiyong Xia ${ }^{4}$, Yuanzheng Gong ${ }^{1}$, \\ Zichao Wan ${ }^{1}$, Daqi Lv ${ }^{1}$, Rui Tan ${ }^{1}$, Wenfei Zhu ${ }^{1}$, Ruizhe Shen ${ }^{1}$, Xin Li ${ }^{1}$, Xuena Yu ${ }^{1}$, Shiyi Chen ${ }^{1}$, Liming Zeng ${ }^{1}$, and \\ Xiaofeng Huang 4 \\ ${ }^{1}$ State Key Joint Laboratory of Environmental Simulation and Pollution Control, International Joint Laboratory for Regional \\ Pollution Control, Ministry of Education (IJRC), College of Environmental Sciences and Engineering, Peking University, \\ Beijing, 100871, China \\ ${ }^{2}$ Collaborative Innovation Center of Atmospheric Environment and Equipment Technology, Nanjing University of \\ Information Science and Technology, Nanjing, 210044, China \\ ${ }^{3}$ School of Atmospheric Sciences, Sun Yat-sen University, Zhuhai, 519082, China \\ ${ }^{4}$ Key Laboratory for Urban Habitat Environmental Science and Technology, School of Environment and Energy, \\ Peking University Shenzhen Graduate School, Shenzhen, 518055, China
}

Correspondence: Song Guo (songguo@pku.edu.cn)

Received: 19 December 2020 - Discussion started: 15 January 2021

Revised: 24 March 2021 - Accepted: 17 April 2021 - Published: 25 May 2021

\begin{abstract}
To investigate the composition, variation, and sources of nitrated phenols (NPs) in the winter of Beijing, gas-phase NPs were measured by a chemical ionization long time-of-flight mass spectrometer (CI-LToF-MS). A box model was applied to simulate the secondary formation process of NPs. In addition, the primary sources of NPs were resolved by a non-negative matrix factorization (NMF) model. Our results showed that secondary formation contributed $38 \%, 9 \%, 5 \%, 17 \%$, and almost $100 \%$ of the nitrophenol (NP), methyl-nitrophenol (MNP), dinitrophenol (DNP), methyl-dinitrophenol (MDNP or DNOC), and dimethyl-nitrophenol (DMNP) concentrations. The phenol$\mathrm{OH}$ reaction was the predominant loss pathway (46.7\%) during the heavy pollution episode, which produced the phenoxy radical $\left(\mathrm{C}_{6} \mathrm{H}_{5} \mathrm{O}\right)$. The phenoxy radical consequently reacted with $\mathrm{NO}_{2}$ and produced nitrophenol. By estimating the primarily emitted phenol from the ratio of phenol/CO from freshly emitted vehicle exhaust, this study proposed that oxidation of primary phenol contributes much more nitrophenol $(37 \%)$ than that from benzene oxidation $(<1 \%)$ in the winter of Beijing. The latter pathway was widely used in models and might lead to great uncertainties. The source apportion-
\end{abstract}

ment results by NMF indicated the importance of combustion sources $(>50 \%)$ to the gas-phase NPs. The industry source contributed $30 \%$ and $9 \%$ to DNP and MDNP, respectively, which was non-negligible. The concentration weighted trajectory (CWT) analysis demonstrated that regional transport from provinces that surround the Yellow and Bohai seas contributed more primary NPs to Beijing. Both primary sources and secondary formation at either local or regional scale should be considered when making control policies of NPs.

\section{Introduction}

Nitrated phenols (NPs) refer to aromatic compounds with at least a hydroxyl $(-\mathrm{OH})$ group and a nitro $\left(-\mathrm{NO}_{2}\right)$ group. They are crucial species in forest decline (Grosjean and Williams, 1992; Qingguo Huang et al., 1995). In addition, NPs are important components of brown carbon with absorption properties in near-UV light (Iinuma et al., 2010; Laskin et al., 2015; C. Lu et al., 2019a; Xie et al., 2017). As a result, NPs have been widely detected around the world in the gas and particle phase, in fog, cloud, rain, snow, and surface water 
since the 1980s (Harrison et al., 2005). Among these studies, gas-phase NPs were detected in urban, suburban, and remote regions (Mohr et al., 2013; Morville et al., 2006; Priestley et al., 2018). The concentrations of NPs varied significantly from place to place (Harrison et al., 2005). Beijing is the capital city of China which has a population of more than 20 million and more than 5 million private cars (Tang et al., 2021); yet the occurrence of gas-phase NPs in Beijing is rarely investigated. Most of the studies in Beijing focused on particle-phase NPs (or so-called nitro-aromatic compounds, NACs) (Li et al., 2020; Wang et al., 2019). The estimated gasphase concentration of nitrophenol from the particle phase was as much as $600 \mathrm{ppt}$ without direct evidence of measurement (Wang et al., 2019). Consequently, it is of vital importance to identify the concentration and sources of NPs in Beijing.

Gas chromatography-mass spectrometer (GC-MS) and high-performance liquid chromatography-mass spectrometer (HPLC-MS) instruments were commonly used to quantify the ambient concentration of NPs with accurate molecular information (Belloli et al., 1999; Harrison et al., 2005; Lüttke et al., 1997). Conversely, the pretreatment procedure is frustrating, and the time resolution is rather low. The measurement of reactive atmospheric phenolic compounds demands a real-time, high time resolution, and accurate method. In recent years, the chemical ionization mass spectrometer (CIMS) has become popular for its high accuracy and time resolution $(<1 \mathrm{~s})$ (Priestley et al., 2018; Yatavelli et al., 2012). The oxidation routines of different organic compounds have been clarified by the online approach of CIMS (Bannan et al., 2015; Mohr et al., 2013; Yuan et al., 2016; Zheng et al., 2015). Accordingly, CIMS is a powerful approach in measuring atmospheric organic compounds, which is appropriate for the quantification of ambient NPs.

NPs in the atmosphere come from both primary emission and secondary formation. Coal combustion, biomass burning, and vehicle exhaust are the common sources of primary NPs emissions (C. Lu et al., 2019a, b; Wang et al., 2017). Additionally, phenolate compounds are widely used as drugs, plastics, and antioxidants (Heberer and Stan, 1997). Dinitrophenol (DNP) and methyl-dinitrophenol (MDNP, also known as DNOC) have been used as pesticides for more than 50 years (Chaara et al., 2010). As a result, the pesticide industry may be a probable source of DNP and MDNP emissions. Despite the complex primary emissions, the secondary formation of atmospheric NPs is also crucial (Harrison et al., 2005; Yuan et al., 2016). Photooxidation of benzene, toluene, and xylene by $\mathrm{OH}$ and $\mathrm{NO}_{3}$ forms phenol, cresol, and xylenol, respectively. The further oxidation of these phenols results in the secondary formation of nitrophenol (NP), methyl-nitrophenol (MNP), and dimethylnitrophenol (DMNP) (Harrison et al., 2005). However, not only do the atmospheric phenols come from the oxidation of aromatics, but they are also emitted directly from vehicle exhaust, biomass burning, and other primary sources (Ino- mata et al., 2014; Laskin et al., 2015; Sekimoto et al., 2013). To make more useful control strategies of NPs, it is of vital importance to distinguish the proportion of secondary formation of NPs from benzene and that from the oxidation of the directly emitted phenols.

In the present work, we conducted high time resolution measurement of the gas-phase nitrated phenols using a chemical ionization long time-of-flight mass spectrometer (CILToF-MS, CIMS) in the winter of Beijing. The secondary formation process of NPs was simulated by a box model. The primary phenol oxidation process was distinguished from benzene oxidation to investigate its role in the secondary formation of NPs. Non-negative matrix factorization (NMF) and concentration weighted trajectory (CWT) analysis were utilized to conduct the source apportionment and identify the potential region of these sources.

\section{Materials and methods}

\subsection{Measurements of nitrated phenols and other gaseous pollutants}

\subsubsection{Measurement location}

The sampling site is at an urban site, i.e., Peking University Atmosphere Environment MonitoRing Station (PKUERS; $39^{\circ} 59^{\prime} \mathrm{N}, 116^{\circ} 18^{\prime} \mathrm{E}$ ), which is located on the campus of Peking University. Details about this site are reported in previous work (Guo et al., 2012, 2014; Wehner et al., 2008). In brief, the site is situated about $20 \mathrm{~m}$ a.g.l. No significant sources are found nearby. The compositions and variations of air pollutants at this site are representative of the urban area of Beijing (Guo et al., 2020; Wang et al., 2019; Tang et al., 2018). The measurement was conducted from 1 to 31 December 2018, which was in the winter of Beijing.

\subsubsection{Quantification of gas-phase nitrated phenols}

A chemical ionization long time-of-flight mass spectrometer (CI-LToF-MS; Aerodyne Research, Inc.) equipped with a nitrate ionization source was utilized to determine the gasphase concentrations of NPs. Detailed information about the instrumentation of CIMS can be found elsewhere (Bean and Hildebrandt Ruiz, 2016; Fang et al., 2020). Briefly, in a highpurity flow of nitrogen, an X-ray source was used to ionize the reagent gas, which then entered the ion-molecule region (IMR). Nitrated phenols reacted with these reagent ions, i.e., $\mathrm{NO}_{3}^{-}\left(\mathrm{HNO}_{3}\right)_{0-2}$, to form the product ions. Seven NPs were quantified in the present work, i.e., nitrophenol (NP), methylnitrophenol (MNP), dimethyl-nitrophenol (DMNP), nitrocatechol (NC), methyl-nitrocatechol (MNC), dinitrophenol (DNP), and methyl-dinitrophenol (MDNP or DNOC). The original time resolution of the concentration of NPs was $1 \mathrm{~s}$. The CIMS data were processed by Tofware 3.0.3 (Tofwerk AG, Aerodyne Research) in Igor Pro 7.08 (WaveMetrics Inc) 
(Stark et al., 2015; Yatavelli et al., 2014). The chemical formula compositions of these NPs were detected by the timeof-flight mass spectrometer (ToF-MS). See more detail in Fig. S1 in the Supplement.

\subsubsection{Calibration of gas-phase nitrated phenols}

The calibration of CIMS is challenging because of the wide detection range of CIMS and unknown molecular structures of the compound detected by the ToF-MS (Priestley et al., 2018). In this study, we used a Dynacalibrator ${ }^{\circledR}$ permeator (Modle 500, VICI, MetronIcs Inc.) to generate nitrophenol standard gas with high stability and accuracy. The permeation rate of the NP permeation tube (Dynacal ${ }^{\circledR}$, VICI) is

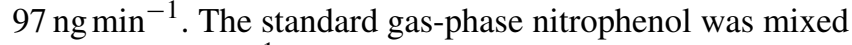
with $2-15 \mathrm{~L} \mathrm{~min}^{-1}$ synthetic air in the permeator to create different concentrations and then was diluted by $8 \mathrm{~L} \mathrm{~min}^{-1}$ synthetic air. The calibration curve was made by plotting the actual gas-phase NP concentration as the function of ion signals detected. The uncertainty in quantifying other NPs from the sensitivity of NP ranged from $-26 \%$ to $22 \%$ (Schwantes et al., 2017; Yuan et al., 2016). The addressed NPs calibrated by NP were correct in concentration levels and magnitudes. See more detail in Fig. S2 in the Supplement.

\subsubsection{Supplementary measurements}

Relative humidity (RH) and temperature $(T)$ were measured by Met One Instruments, Inc. at the PKUERS site. NO$\mathrm{NO}_{2}-\mathrm{NO}_{x}$ gas analyzers (Thermo Fisher Scientific, model 42i-TLE) and a UV photometric $\mathrm{O}_{3}$ analyzer (Thermo Fisher Scientific model 49i) were utilized to measure the concentration of $\mathrm{NO}, \mathrm{NO}_{2}, \mathrm{NO}_{x}$, and $\mathrm{O}_{3}$. Volatile organic compounds (VOCs) were measured by an online gas chromatography system equipped with a mass spectrometer and a flame ionization detector (online GC-MS/FID; Tianhong, China) (Liu et al., 2005; Shao et al., 2009). In total, 98 kinds of VOCs were measured, including alkanes, alkenes, aromatics, acetylene, and oxygenated volatile organic compounds (OVOCs). Detailed information of these VOCs can be found elsewhere (Yu et al., 2021; Yuan et al., 2013).

\subsection{Estimation of primary sources and secondary formation of nitrated phenols}

Overall, a zero-dimensional box model equipped with the Master Chemical Mechanism (MCMv3.3.1) was utilized to simulate the secondary formation process of NPs. NPs from the oxidation of primary phenol and benzene were apportioned. The primary emission was calculated by the subtraction from the total measured concentration and then resolved by non-negative matrix factorization (NMF). The concentration weighted trajectory (CWT) analysis was also utilized to identify the source regions of the regional transport.

The data were analyzed by R 3.6.3 (R Core Team, 2015), including the packages openair (Ropkins and Carslaw, 2012),
Biobase (Huber et al., 2015), NMF (Gaujoux and Seoighe, 2010), and ggplot2 (Valero-Mora, 2010).

\subsubsection{Estimation of secondary formation of nitrated phenols by a box model}

The secondary formation process of NPs was simulated by a zero-dimensional box model equipped with the Master Chemical Mechanism (MCMv3.3.1; http://mcm.york.ac.uk/ home.htt, last access: 2 March 2021). The related mechanism is presented in Fig. 1. Water vapor, temperature, pressure, and the concentration of $\mathrm{NO}, \mathrm{NO}_{2}, \mathrm{O}_{3}$, and $\mathrm{CO}$ were used to constrain the model simulation in all scenarios. The basic model constrained the concentration of benzene, toluene, and xylene measured by an online GC-MS/FID. This basic model illustrated the secondary formation process of the NPs from the oxidation of aromatic hydrocarbons. However, less than $1 \%$ of the total nitrophenol (NP) concentration could be explained (Fig. S3 in the Supplement), which was inconsistent with the estimation from the NP/CO ratio in other studies (Inomata et al., 2013; Sekimoto et al., 2013), implying there are probably missing sources of phenol. For instance, nitrophenol not only comes from the benzenephenol-nitrophenol oxidation pathway, but it also originates from the oxidation of directly emitted phenol (so-called primary phenol). As a result, we constrained the phenol concentration rather than benzene to investigate the nitrophenol formation from primary phenol. As the concentration of primary phenol was not determined in this study, we used the ratio of $\mathrm{phenol} / \mathrm{NO}_{y}\left(0.3 \mathrm{pptppb}^{-1}\right)$ and phenol/CO $\left(0.4 \mathrm{ppt} \mathrm{ppb}^{-1}\right)$ from fresh emitted vehicle exhaust (Inomata et al., 2013; Sekimoto et al., 2013). Atmospheric CO is inert so that the VOC to CO ratio is widely used to quantify anthropogenic emissions ( $\mathrm{Li}$ et al., 2019). The estimation of phenol from the phenol/CO ratio showed good agreement in trend and concentration level (Fig. S3). The estimated phenol concentration in this approach was comparable to the measured concentration from other sites (Table 1). As a result, the budget analysis and the source apportionment were composed based on the constrained results of estimated phenol concentration by the ratio of phenol/CO.

\subsubsection{Source apportionment of nitrated phenols by non-negative matrix factorization (NMF)}

In this work, a non-negative matrix factorization (NMF) approach was used to estimate the primary contributions of NPs. The total primary NPs were calculated by subtracting the secondary NPs from the box model by the total NPs. NMF is a model that is good at dealing with multidimensional data and shares the same principle with the well-known positive matrix factorization (PMF). In principle, NMF decomposes a matrix $\mathbf{X}$ (the concentration matrix) into two non-negative matrices $\mathbf{W}$ (the source contribution 


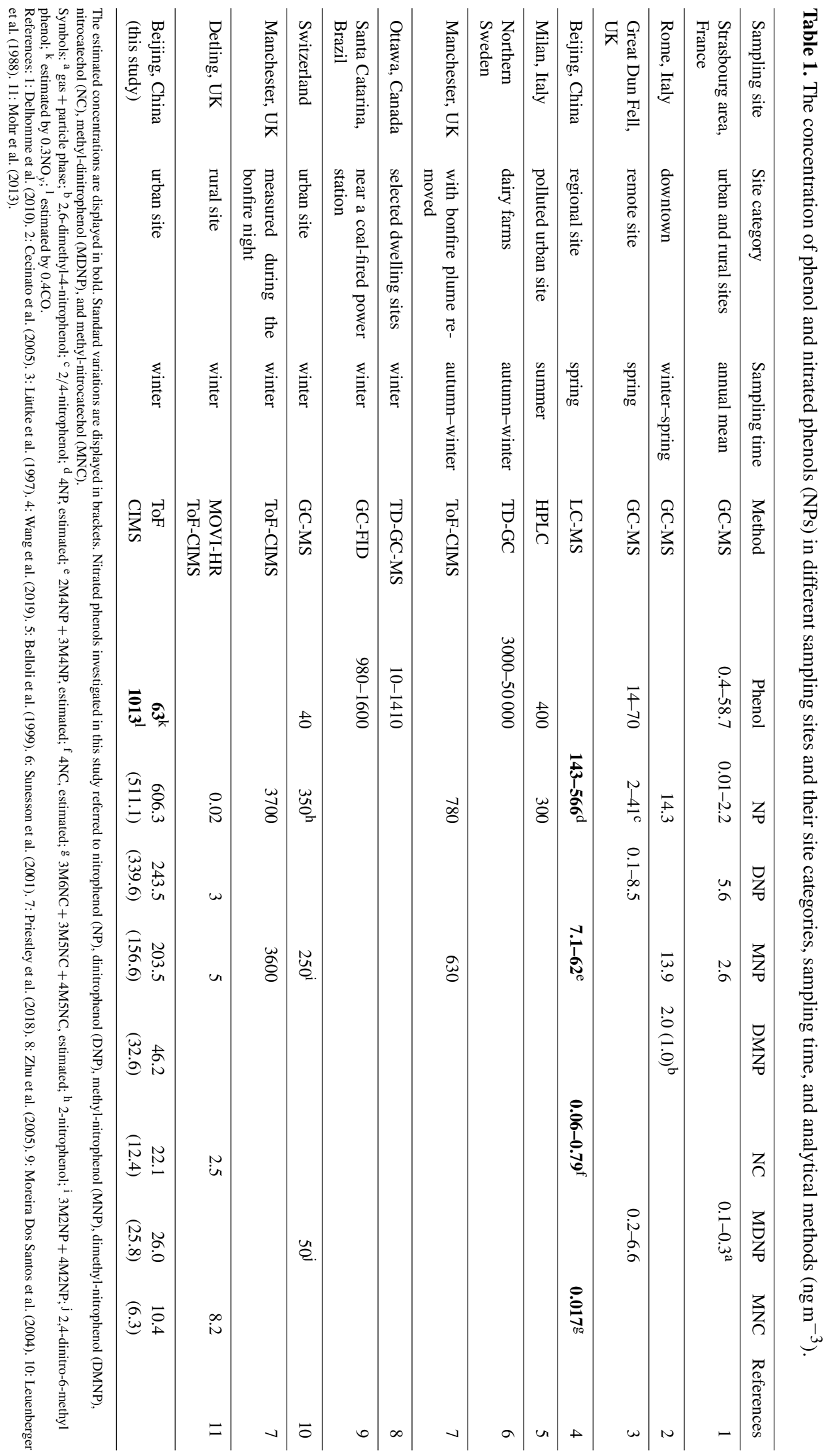


Branching ratios

Rate constants $\left(\mathrm{cm}^{3}\right.$ molecule $\left.\mathrm{e}^{-1} \mathrm{~s}^{-1}\right)$

Basic model

Phenol from benzene oxidation<smiles>Oc1ccccc1</smiles>

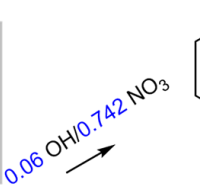<smiles>Clc1ccccc1</smiles><smiles>O=[N+]([O-])c1cc(O)c([N+](=O)[O-])c([N+](=O)[O-])c1</smiles>

Other model scenarios

Directly emitted phenol (estimated)<smiles>Oc1ccccc1</smiles><smiles>C1[13CH][13CH]1</smiles><smiles></smiles>
phenol-OH: $4.7 \times 10^{-13} \operatorname{EXP}(1220 / \mathrm{T})$ phenol-NO3: $9.0 \times 10^{-14}$
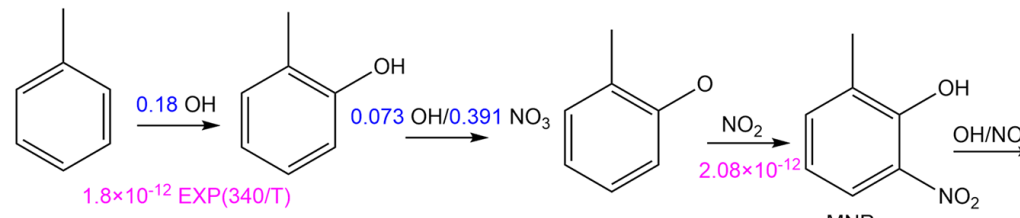
MNP<smiles>Nc1ccc(O)c(O)c1</smiles>

NC

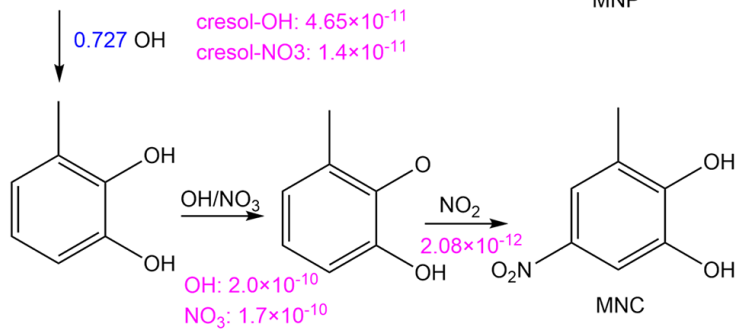<smiles>Cc1cc([N+](=O)[O-])cc([N+](=O)[O-])c1O</smiles>
MDNP<smiles>Cc1cccc(C)c1</smiles><smiles>Cc1ccc(C)cc1</smiles><smiles>Cc1c(O)ccc([18O])c1[N+](=O)[O-]</smiles><smiles>Cc1cccc(C)c1C</smiles><smiles>Cc1c([N+](=O)[O-])cc([N+](=O)[O-])c(O)c1C</smiles>

Figure 1. Mechanism related to the secondary formation of the nitrated phenols (NPs) in MCM 3.3.1 applied in this study. Different model scenarios differed in the constraints of the precursors. The basic model constrained the concentration of benzene by measurement from an online GC-MS/FID. The other model scenarios constrained primary phenol concentration rather than benzene estimated by the ratio of phenol/NO $\mathrm{NO}_{y}$ or phenol/CO from fresh vehicle exhaust.

matrix) and $\mathbf{H}$ (the source profile matrix) (Devarajan, 2008).

$\mathbf{X} \approx \mathbf{W H}$,

where $\mathbf{X}, \mathbf{W}$, and $\mathbf{H}$ are $n \times p, n \times r$, and $r \times p$ non-negative matrices, and $r$ is a positive integer that indicates the number of the factors.

The approach of NMF is to minimize the estimation of $\mathbf{W}$ and $\mathbf{H}$ :

$\min _{\mathbf{W}, \mathbf{H} \geq 0} \underbrace{[D(\mathbf{X}, \mathbf{W H})+R(\mathbf{W}, \mathbf{H})]}_{=F(\mathbf{W}, \mathbf{H})}$, where $D$ is the Kullback-Leibler (KL) divergence utilized in this study:

$D: A, B \longmapsto \mathrm{KL}(A \| B)=\sum_{i, j} a_{i, j} \log \frac{a_{i, j}}{b_{i, j}}-a_{i, j}+b_{i, j}$.

$R(\mathbf{W}, \mathbf{H})$ is an optional regularization function enforcing the constraints of $\mathbf{W}$ and $\mathbf{H}$ (Gaujoux and Seoighe, 2015).

NMF has been widely used in facial pattern recognition (Lee and Seung, 1999), signal and data analytics (Fu et al., 2019), and computational biology (Devarajan, 2008). Strictly speaking, PMF is a specific NMF model used in environmental sciences (Paatero and Tapper, 1994). In recent years, NMF has turned out to be a powerful technique to distinguish oxygenated organic compounds from numerous urban sources 
(Karl et al., 2018). Compared with PMF, the NMF approach is equipped with more algorithms for matrix factorization, e.g., brunet (Brunet et al., 2004), lee (Lee and Seung, 2001), nsNMF (Pascual-Montano et al., 2006), and other methods listed on the NMF vignette (Gaujoux and Seoighe, 2015). In addition, the cophenetic coefficient is a fundamental way to give the optimal choice of factorization rank $r$, while the consensus map approach avoids overfitting. The advantage of NMF is the convincing factor choice rather than the casual selection by PMF.

\subsubsection{Concentration weighted trajectory (CWT) analysis}

Back trajectory analysis was accomplished by the interface of HYSPLIT (Rolph et al., 2017; Stein et al., 2015) and R. The primary source resolved by NMF was then distinguished by the concentration weighted trajectory (CWT) approach (Seibert et al., 1994) in an attempt to identify the location of the probable source. The CWT calculated the logarithmic mean concentration of NPs for every grid as the Eq. (4). Normally, a high value of $\bar{C}_{i j}$ indicates higher concentration at the grid $(i, j)$.

$\ln \left(\overline{C_{i j}}\right)=\frac{1}{\sum_{k}^{N} \tau_{i j k}} \sum_{k}^{N} \ln \left(c_{k}\right) \tau_{i j k}$,

where $i$ and $j$ are the indices of the grid cell $(i, j), k$ and $N$ are the trajectory index and the total number of trajectories, $c_{k}$ is the concentration of NPs when trajectory $k$ passes by, and $\tau_{i j k}$ is the resistance time of trajectory $k$ in the cell $(i, j)$ (Ropkins and Carslaw, 2012).

\section{Results and discussions}

\subsection{Overview of the meteorological conditions and air pollutants}

The measurement started with a heavy pollution episode from 1 to 2 December, with an average wind speed of $0.61 \mathrm{~m} \mathrm{~s}^{-1}$, an average RH of $63 \%$, and average concentration of $\mathrm{PM}_{2.5}, \mathrm{NO}_{y}$, and $\mathrm{CO}$ of $166 \mu \mathrm{g} \mathrm{m}^{-3}, 118 \mathrm{ppb}$, and $1912 \mathrm{ppb}$, respectively. The average concentration of $\mathrm{PM}_{2.5}, \mathrm{NO}_{y}$, and $\mathrm{CO}$ with the heavy pollution removed was $37 \mu \mathrm{g} \mathrm{m}^{-3}, 49 \mathrm{ppb}$, and $598 \mathrm{ppb}$, respectively. The average wind speed from 3 to 31 December was $1.96 \mathrm{~m} \mathrm{~s}^{-1}$, and the average RH was $20 \%$. The heavy pollution episode was accompanied by high relative humidity and slow wind speed. The time series of wind speed, $\mathrm{RH}, \mathrm{PM}_{2.5}, \mathrm{NO}_{y}$, and $\mathrm{CO}$ during the whole sampling period can be found in Fig. S4 in the Supplement.

The concentration and composition of gas-phase NPs during the measurement are displayed in Fig. 2. The average concentrations of NPs (total nitrated phenols) during and without the heavy pollution episode were $1213 \pm 769$ ppt and
$170 \pm 132 \mathrm{ppt}$, while nitrophenol (NP) was the predominant species, with a concentration of $662 \pm 459 \mathrm{ppt}(55 \%)$ and $97 \pm 83$ ppt $(57 \%)$, respectively. To compare the representative concentrations of NP all around the world, we evaluated the concentration in Beijing (with the episode removed) and other cities in Table 1. The concentrations were converted to nanograms per cubic meter $\left(\mathrm{ng} \mathrm{m}^{-3}\right)$, with the aim of a wide-ranging comparison. From Table 1, it is noticeable that the concentrations of NPs ranged extensively from time to time, with relatively higher values in winter. As for sampling sites, urban sites and those influenced by biomass burning were more likely to be polluted by NPs. Different analytical methods showed discrepancies; this might be clarified by their distinct instrumental principles. Likewise, the concentrations of NPs in Beijing were higher than those in rural and remote sites. Nevertheless the concentrations of NPs were much lower than the sites that were influenced by biomass burning (Priestley et al., 2018). The concentration of gasphase DNP in Beijing was considerably higher than that of other sites.

Composition of NPs in Beijing during the episode and the rest period showed no significant difference, except that the proportion of DNP was $24 \%$ during the episode and $17 \%$ without the episode, respectively (Fig. 2). In contrast, a large proportion of MNP (comparable to nitrophenol) was found in other cities (Cecinato et al., 2005; Leuenberger et al., 1988; Priestley et al., 2018). The non-negligible secondary formation of nitrophenol from phenol oxidation was a plausible explanation for the higher concentration of DNP in Beijing.

The diurnal variations of NPs were exhibited in Fig. 3. Interestingly, NPs with different functional groups revealed different diurnal patterns. Nitrophenol (NP), MNP, and DMNP (NPs with one $-\mathrm{OH}$ group and one $-\mathrm{NO}_{2}$ group) demonstrated higher concentrations at night and lower concentrations during the day. The strong loss of gas-phase NPs due to photolysis or $\mathrm{OH}$ reaction during the daytime (Harrison et al., 2005; Yuan et al., 2016) might be a plausible explanation. Additionally, the stable boundary layer at night might cause the accumulation of NPs as well. This indicated consistency with the studies carried out during the UBWOS 2014 campaign (Yuan et al., 2016). Nonetheless, NC and MNC (NPs with two $-\mathrm{OH}$ groups and one $-\mathrm{NO}_{2}$ group) displayed a small peak at about 10:00 and revealed high concentrations at night. DNP and MDNP (NPs with one -OH group and two $-\mathrm{NO}_{2}$ groups) displayed distinct patterns from either NP or NC. DNP accumulated during the afternoon and began to decline after 17:00, suggesting that $\mathrm{NO}_{3}$ oxidation of DNP might be a non-negligible sink. The diurnal profile of MDNP did not vary much during the whole day, with a slight increase at night. 


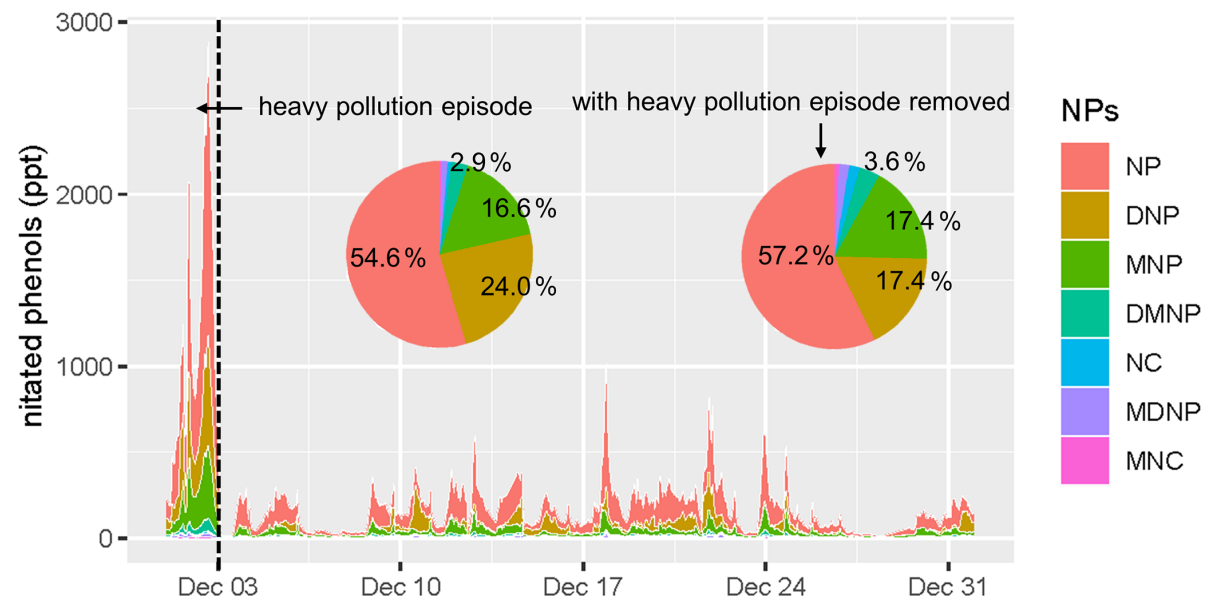

Figure 2. Time series (local time) and compositions of nitrated phenols (NPs) during the heavy pollution episode (1 and 2 December) and with the heavy pollution episode removed (3 to 31 December). NPs in the legend referred to nitrophenol (NP), dinitrophenol (DNP), methyl-nitrophenol (MNP), dimethyl-nitrophenol (DMNP), nitrocatechol (NC), methyl-dinitrophenol (MDNP), and methyl-nitrocatechol (MNC).

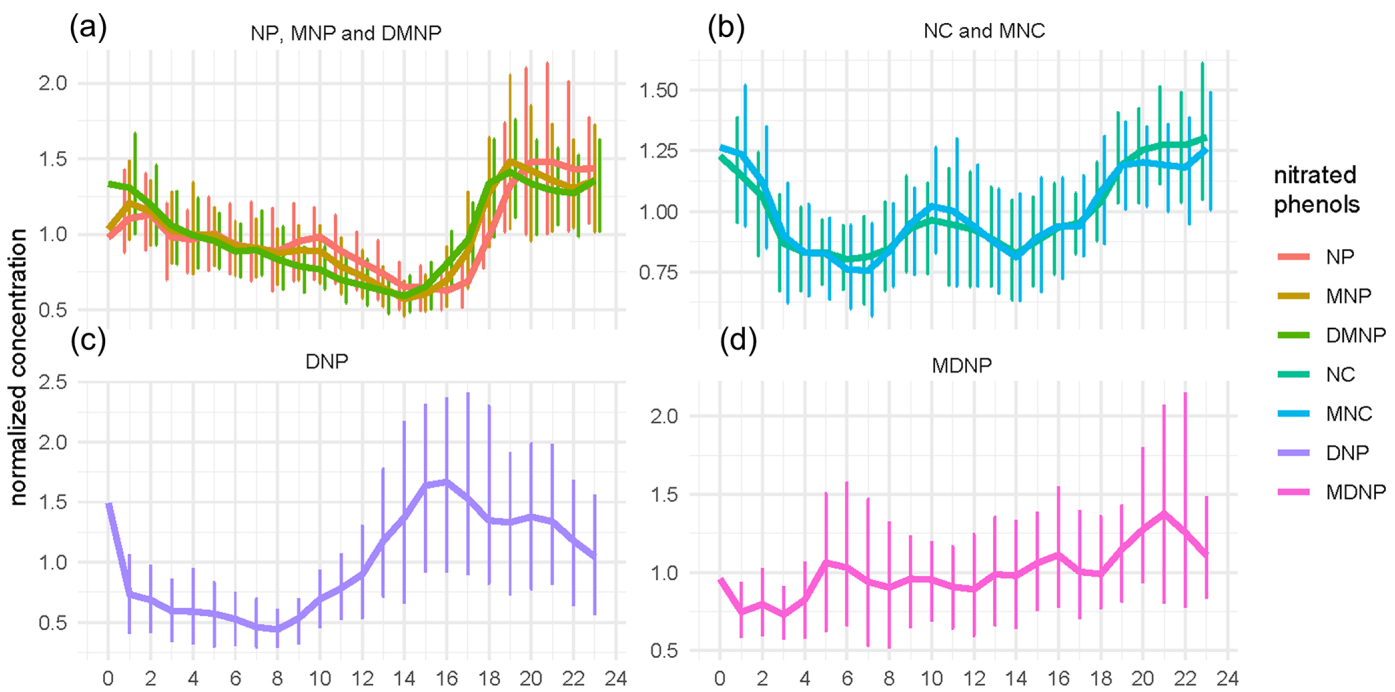

Figure 3. Diurnal profiles of nitrated phenols (NPs) with $95 \%$ confidence interval shown by the error bars. The concentration of NPs was normalized by their mean values. (a) Diurnal profiles of nitrophenol (NP), methyl-nitrophenol (MNP), and dimethyl-nitrophenol (DMNP). These are NPs with one -OH group and one $-\mathrm{NO}_{2}$ group. (b) Diurnal profiles of nitrocatechol (NC) and methyl-nitrocatechol (MNC). These are NPs with two $-\mathrm{OH}$ groups and one $-\mathrm{NO}_{2}$ group). Diurnal profiles of (c) dinitrophenol (DNP) and (d) methyl-dinitrophenol (MDNP). These are NPs with one $-\mathrm{OH}$ group and two $-\mathrm{NO}_{2}$ groups.

\subsection{Estimation of secondary formation and budget of nitrated phenols}

In this section, gas-phase nitrophenol (NP), MNP, DMNP, DNP, and MDNP were taken into account because of their higher concentrations and larger fractions in the gas phase. The concentrations of gas-phase NC and MNC were rather low $(<4 \%$ that of nitrophenol) in this study, and they were found mainly in the particle phase (Wang et al., 2019). As a result, they were excluded from the box model results and the source apportionment.
Overall, the secondary formation accounted for $38 \%, 9 \%$, $5 \%$, and $17 \%$ for ambient nitrophenol (NP), MNP, DNP, and MDNP respectively. Almost $100 \%$ of DMNP could be explained by the oxidation of xylenes. The simulation results can be found in Fig. S3. For nitrophenol, the simulation of the basic model and with primary phenol estimated by $\mathrm{NO}_{y}$ was quite similar (both the contributions of these two model scenarios were less than $1 \%$ ). When considering the primary emission of phenol by the ratio of phenol/CO (see Sect. 2.2.1), significant improvement of NP was found $(37 \%)$. The results indicated a sensitivity of NP production 
from the primarily emitted phenol so that when NP control policies are made, it is of vital importance to control the emission of phenol rather than the classical precursor, i.e., benzene. Meanwhile, the nonlinear effect of oxidation capacities and radical concentration might result in an improvement of MNP or MDNP when phenol is constrained. The model results of MDNP did not vary much as the xylenexylenol-MDNP pathways can explain most of the secondary formation pathways of MDNP.

\subsubsection{Production and loss of phenol and nitrophenol}

Time series and diurnal profile of the loss of phenol during and without the heavy pollution episode were shown in Fig. 4. It was obvious that the $\mathrm{OH}$ loss mainly took place during the day, while $\mathrm{NO}_{3}$ loss mainly happened at night. However, the fraction of these two pathways diverged dramatically when taking the episode into account. During the heavy pollution episode, $46.7 \%$ of phenol was lost from the pathway of the $\mathrm{OH}$ reaction, which caused the production of the phenoxy radical $\left(\mathrm{C}_{6} \mathrm{H}_{5} \mathrm{O}\right) . \mathrm{C}_{6} \mathrm{H}_{5} \mathrm{O}$ then reacted with $\mathrm{NO}_{2}$ and formed nitrophenol (Berndt and Böge, 2003). With the heavy pollution episode removed, the proportion of the $\mathrm{C}_{6} \mathrm{H}_{5} \mathrm{O}$ production pathway of the $\mathrm{OH}$ reaction was only $5.4 \%$. The phenol-OH reaction which produced catechol (which then reacted with $\mathrm{OH} / \mathrm{NO}_{3}$ and $\mathrm{NO}_{2}$ to produce $\mathrm{NC}$ ) was the predominant $\mathrm{OH}$ reaction $(21.9 \%)$. The distinct pattern of the phenol-OH pathway which formed $\mathrm{C}_{6} \mathrm{H}_{5} \mathrm{O}$ indicated a probable source of the nitrophenol accumulation during the heavy pollution episode. The high atmospheric reactivity and oxidation capacity in Beijing (K. Lu et al., 2019; Yang et al., 2020) might be the foundation of high potential reactivity between phenol and the $\mathrm{OH}$ radical.

The production of nitrophenol displayed two peaks at about 08:00 and 18:00, while the loss remained unchanged throughout the whole day. The accumulation of nitrophenol mainly occurred in the afternoon and at night (Fig. 5). The simulation during the heavy pollution episode indicated a strong primary emission on the afternoon of 2 December. The production rate of nitrophenol from 12:00 to 20:00 on 2 December was lower than $10^{5}$ molec. $\mathrm{cm}^{-3} \mathrm{~s}^{-1}$, with a concentration of $1357 \mathrm{ppt}$, while that during the same period on 1 December was higher than $2.5 \times 10^{5}$ molec. $\mathrm{cm}^{-3} \mathrm{~s}^{-1}$, with a concentration of 434 ppt. The underestimation of the box model indicated the occurrence of other sources during the afternoon of 2 December, when primary emissions might be probable.

\subsubsection{Impact of secondary formation on dimethyl-nitrophenol}

The box model simulation of DMNP signified the importance of secondary formation. Production and loss of xylenol and DMNP were shown in Fig. 6. The production and loss showed no distinct patterns during and without the episode.
The production and loss of xylenol displayed peaks at 12:00 and 13:00 respectively. Xylenol mainly accumulated at noon. The reactions with $\mathrm{OH}$ and $\mathrm{NO}_{3}$ radicals accounted for $42.6 \%$ and $42.5 \%$ of the loss of xylenol. The $\mathrm{OH}$ reaction pathway was the predominant loss of xylenol during the daytime and resulted in the formation of DMNP. The production of DMNP increased rapidly from the xylenol- $\mathrm{NO}_{2}$ reaction during the daytime and decreased from noon. The loss of DMNP increased during the afternoon and started to decrease after 18:00. DMNP mainly originated from the secondary formation process, and its accumulation mainly took place in the afternoon, while nitrophenol mainly occurred at night, which was mainly derived from primary emission.

\subsection{Source apportionment of primarily emitted nitrated phenols and the impact of regional transport}

The NMF approach equipped with Brunet, KL, offset, lee, nsNMF, and snmf/l algorithms was used to investigate the sources of primary emitted NPs. These different algorithms were used to choose a better calculation method for the source apportionment. The consensus maps of the simulation are displayed in Fig. S5 in the Supplement. The KL approach was chosen because of its well-estimated pattern. In addition, three to seven factors were tested by NMF so as to get an optimal one. The NMF rank survey is shown in Fig. S6 in the Supplement, in which four factors were chosen.

The mixture coefficients of KL algorithm with factor 4 are displayed in Fig. 7. $\mathrm{SO}_{2}$ was the tracer of factor 1, while aromatics (mainly toluene, xylene, and ethylbenzene) were markers of factor 2. Chloromethane was the tracer of factor 3, while acetylene, trans-2-butene, and 1,3-butadiene were markers of factor 4 . The diurnal patterns of the resolved sources are displayed in Fig. S7 in the Supplement. Combined with results from the markers and the diurnal profiles of the sources, we identified these factors as coal combustion, industry, biomass burning, and vehicle exhaust. As $30.4 \%$ of DNP and $9.2 \%$ of MDNP came from factor 2, the pesticide industry was the most probable contributor.

The source contribution of NPs combining primary emission and secondary formation is displayed in Fig. 8. 58\% of the total NP concentration originated from biomass burning, while $2.4 \%$ was derived from vehicle exhaust. A total of $76.2 \%, 11.8 \%$, and $1.9 \%$ of the total MNP concentration came from biomass burning, coal combustion, and vehicle exhaust, respectively. As for DNP and MDNP, despite $64.9 \%$ and $45.8 \%$ of them being derived from biomass burning, $30.4 \%$ and $9.2 \%$ of DNP and MDNP concentrations resulted from industrial emissions. This suggests that the pesticide industry was still an important source of dinitrophenols.

When coal combustion and biomass burning were regarded as combustion sources, the four-factor results of NMF, as well as the same species in PMF, were comparable (Fig. S8 in the Supplement). The combustion source ac- 
(a) heavy pollution episode

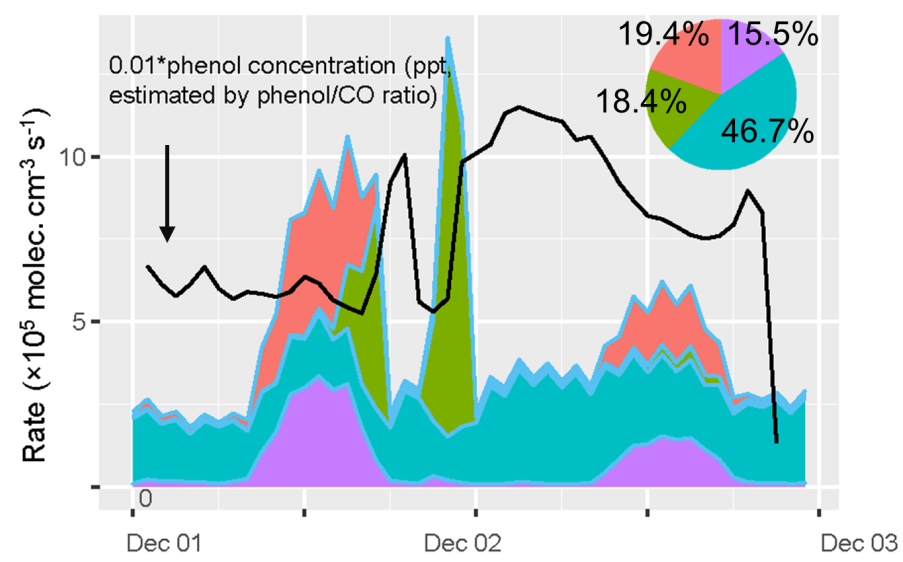

(b) with the episode removed

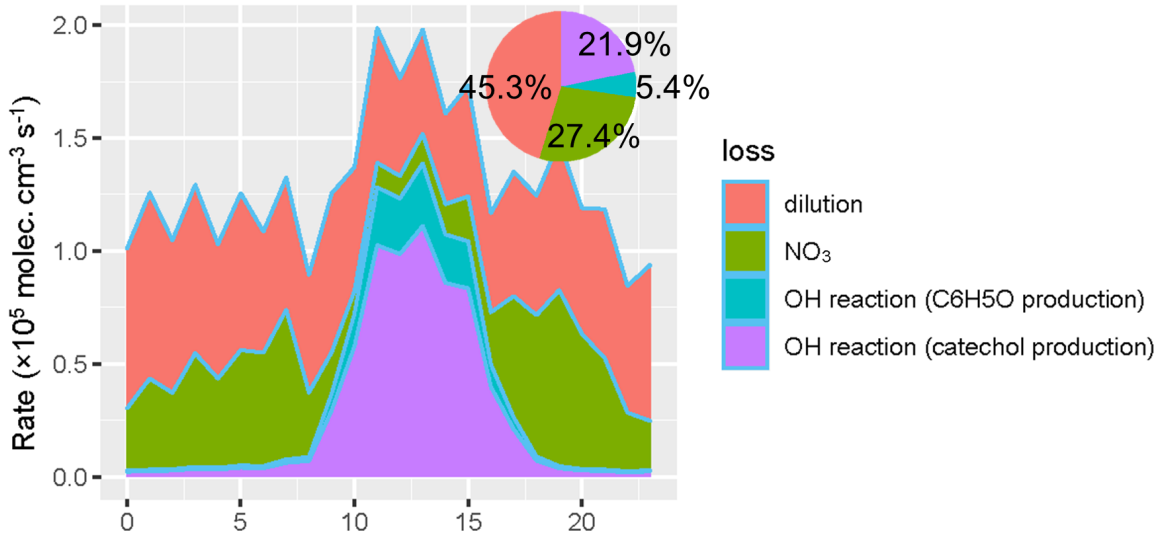

Figure 4. Time series and the loss rate of phenol during the heavy pollution episode (a) and diurnal profile of the loss of phenol with the heavy pollution removed (b).

counts for $61.5 \%, 91 \%, 10.2 \%$, and $38 \%$ of NP, MNP, DNP, and MDNP concentration, respectively. Meanwhile, $80.1 \%$ and $45.3 \%$ of DNP and MDNP concentrations were derived from industry.

Overall, the contribution of primary emission was more important than secondary formation during the measurement. Among all sources, combustion was the predominant one (>50\% of total NPs concentration), which was consistent with other studies focusing on the sources of particulate matter (PM) in the winter of Beijing (Fan et al., 2018; Lyu et al., 2019; Xu et al., 2018). This result was different from the study carried out during the UBWOS 2014 (Yuan et al., 2016 ), in which less than $2 \%$ of NP concentration came from combustion sources. UBWOS 2014 was carried out at an oil and gas production site abundant in the precursors of NPs, i.e., VOCs (such as benzene and toluene) and $\mathrm{NO}_{x}$. Therefore, the secondary process was indeed the predominant one in UBWOS 2014. By contrast, the PKUERS site was far away from industrial zones and combustion sources and was more likely to be influenced by primary emission which came from regional transport nearby.

In this study, the concentration weighted trajectory (CWT) was used to identify the probable source of these primary emissions. Considering the different pollution patterns of the sampling period as well as the amount of data for interpolation in CWT, we divided the sampling period into four sub-periods, i.e., 1-10, 10-15, 15-20, and 20-30 December. CWT analysis was conducted for each period, and the results are displayed in Fig. 9. Strong regional transport was observed during the first period. The biomass burning and industry sources mainly originated from provinces surrounding the Yellow and Bohai seas (especially the city of Tianjin and Shandong Province). Cities located in this area have a long history of pesticide production and use and have been reported to reveal a relatively high residual concentration of pesticide (Li et al., 2018). As for the vehicle exhaust source, local emissions were predominant. The coal combustion source mainly came from Inner Mongolia, which was the 
(a) heavy pollution episode

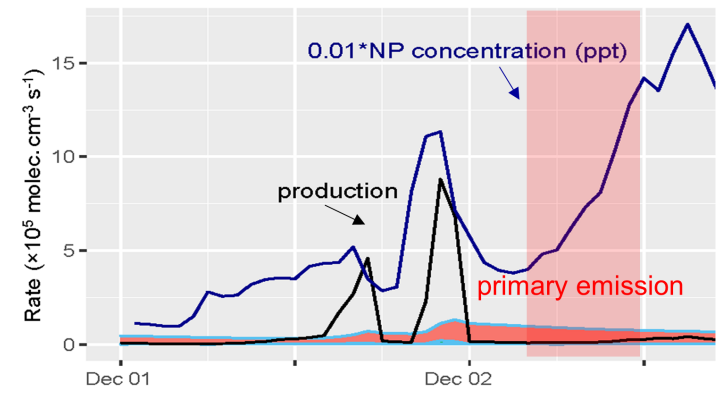

(b) with the episode removed

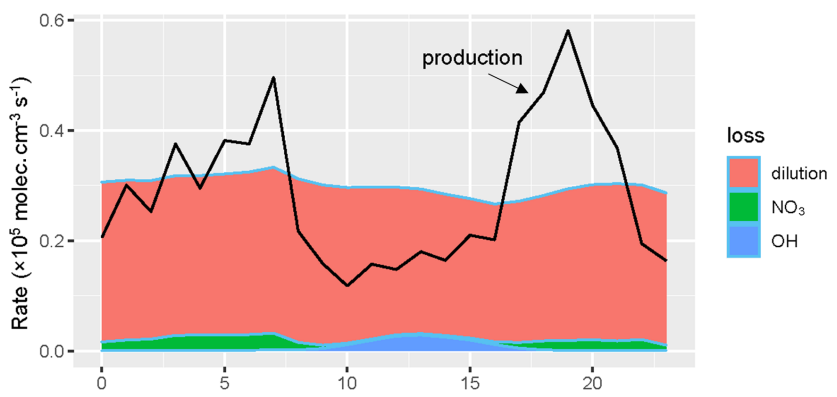

Figure 5. Time series of production and loss of nitrophenol (NP) during the heavy pollution episode (a) and diurnal profiles of production and loss of NP with the heavy pollution removed (b).

(a)

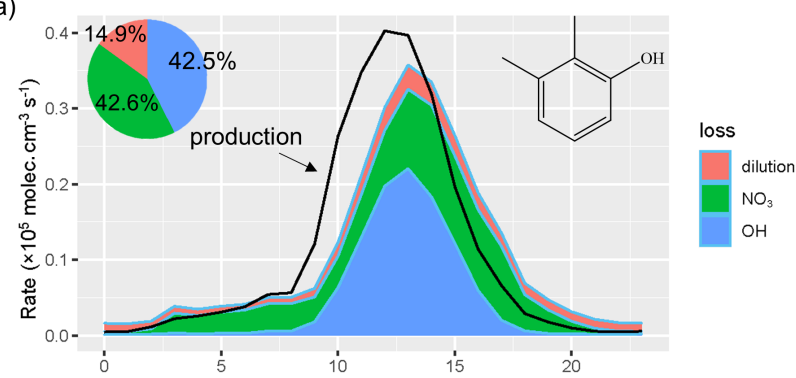

(b)

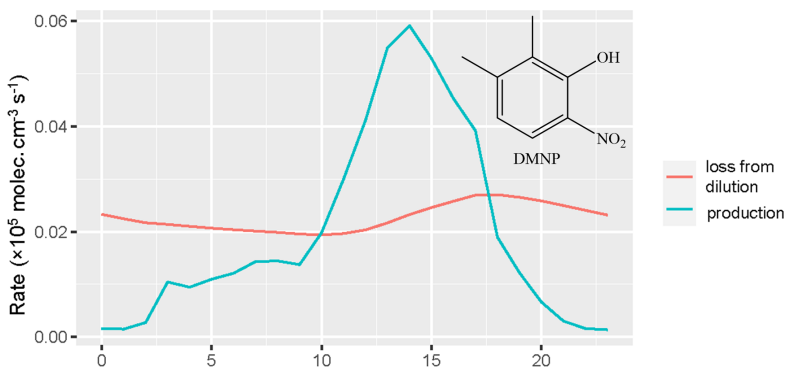

Figure 6. Production and loss of xylenol (a) and DMNP (b) during the sampling period. most coal-abundant area across China (Lv et al., 2020). The CWT analysis proved the accuracy of NMF source apportionment and demonstrated the importance of regional transport when control strategies of NPs are made.

The estimation of secondary formation and primary emission of NPs in this study faced uncertainties, as detailed below. The simulation of NPs in this study was restricted by the estimation of phenol and the mechanisms of MCM, as well as the simulation of the $\mathrm{NO}_{3}$ radical in winter. The box model results of NPs were not identical to secondary formation, and the estimation of primary emissions by subtracting the NPs from the box model results by the total concentration remained uncertain. The main missing reaction pathway in this study is the gas-particle partitioning of NPs. According to Wang et al. (2019), the estimated proportions of gasphase NP, MNP, and DMNP in Beijing were $99.2 \%, 94.9 \%$, and $<1 \%$, respectively. Simulation of NP and MNP without gas-particle partitioning pathways faced small uncertainties as they mainly occurred in the gas phase. The small proportion of DMNP in the gas phase and rather low concentration in the particle phase $\left(0.55 \mathrm{ng} \mathrm{m}^{-3}\right.$, Wang et al., 2019) made the missing pathway not important. Meanwhile, gas-phase DMNP mainly came from secondary formation in this study, and the concentration level of DMNP could be explained well by the box model. As a result, the missing pathway of gas-particle partitioning may not be important in this study.

\section{Conclusions}

Gas-phase nitrated phenols (NPs) were measured using a CI-LToF-CIMS in the winter of Beijing. The total concentration of NPs in winter of Beijing was $1158 \pm 892 \mathrm{ng} \mathrm{m}^{-3}$, which was higher than that in most of the rural and remote sites all around the world. Nitrophenol was the predominant compound, with an average concentration of $606.3 \pm$ $511.1 \mathrm{ng} \mathrm{m}^{-3}$. Strong diurnal patterns were observed, and NPs with different functional groups varied significantly. Nitrophenol displayed higher concentration at night and lower concentration during the day. A box model was utilized to simulate the secondary formation of NPs. $38 \%, 9 \%, 5 \%$, $17 \%$, and almost $100 \%$ of the ambient nitrophenol (NP), MNP, DNP, MDNP, and DMNP could be explained by the oxidation of aromatic precursors. The oxidation of primary phenol estimated by the ratio of phenol/CO from fresh vehicle exhaust accounted for $37 \%$ of the total nitrophenol, while $<1 \%$ might be explained by the oxidation of benzene. The latter pathway was widely used in models and might lead to great uncertainties as the primarily emitted phenol was not considered. Meanwhile, control strategies that focus on the primarily emitted phenol might be more important than benzene when control schemes of NPs are made. Additionally, during the heavy pollution episode, $46.7 \%$ of phenol was lost from the pathway of the $\mathrm{OH}$ reaction to form the phenoxy radical $\left(\mathrm{C}_{6} \mathrm{H}_{5} \mathrm{O}\right)$. The phenoxy radical consequently reacted 


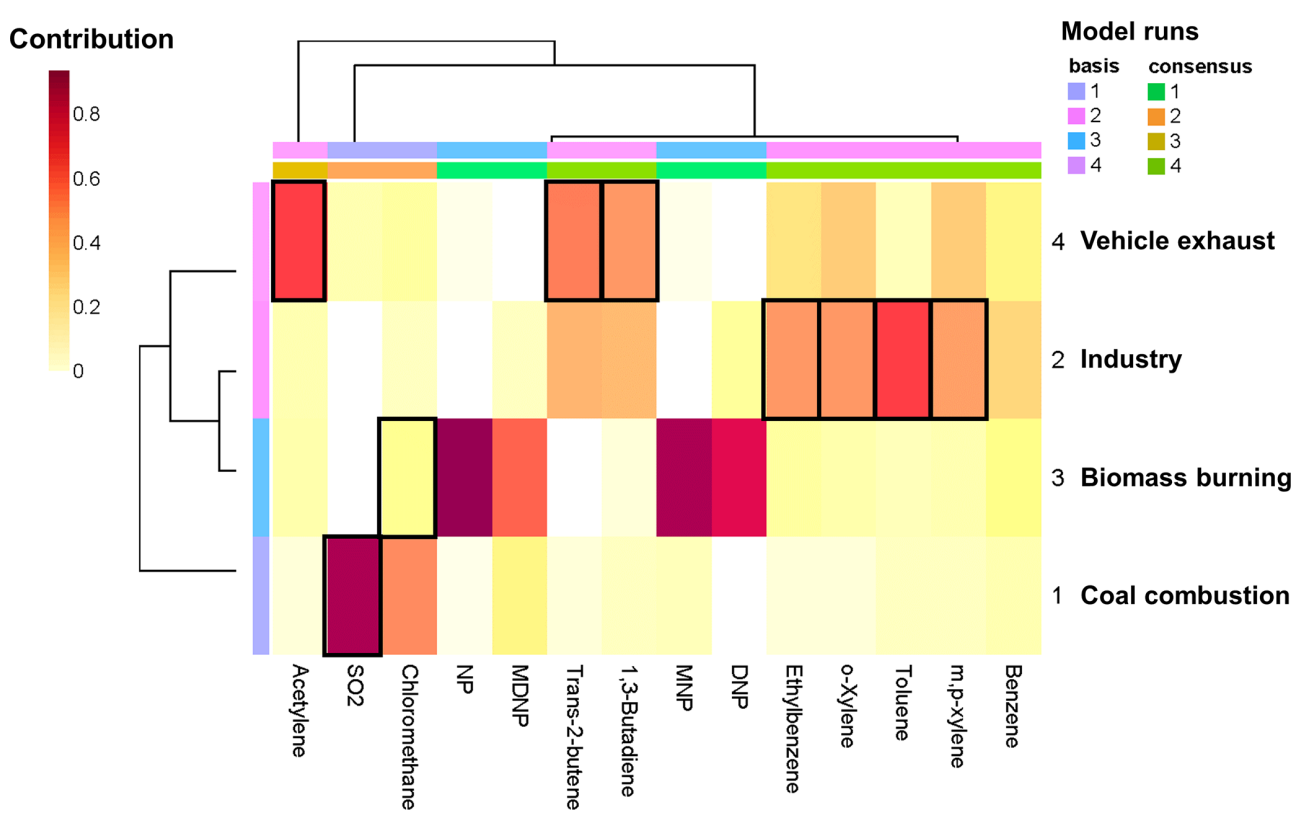

Figure 7. Mixture coefficients of the Kullback-Leibler (KL) algorithm with four factors by non-negative matrix factorization (NMF). Factor 1: coal combustion; factor 2: industry (pesticide); factor 3: biomass burning; factor 4: vehicle exhaust. "Basis" and "consensus" in the legend were the model runs, and the results are displayed in the heatmap.

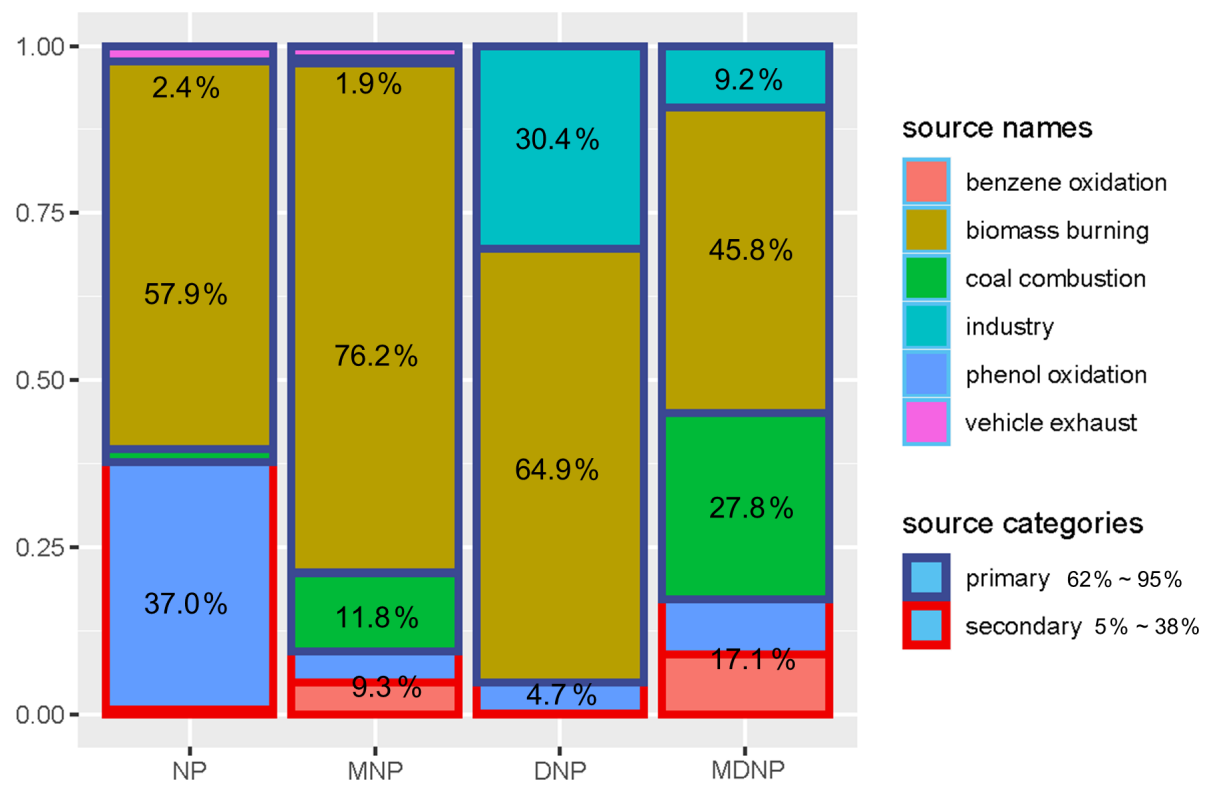

Figure 8. Contribution of primary emission (in dark blue border) and second formation (in red border) of nitrated phenols. Primary emission was classified as biomass burning, coal combustion industry, and vehicle exhaust, which were resolved by non-negative matrix factorization (NMF). NPs in the legend referred to dinitrophenol (DNP), methyl-dinitrophenol (MDNP), methyl-nitrophenol (MNP), and nitrophenol (NP). Secondary formation of nitrophenol was categorized as benzene oxidation $(<1 \%)$ and the oxidation of primarily emitted phenol (phenol oxidation, $37 \%$ ). It was noticeable that nitrophenol derived from the primary phenol oxidation was much more important than the pathway from traditional benzene oxidation in the winter of Beijing. 
(a) Coal combustion

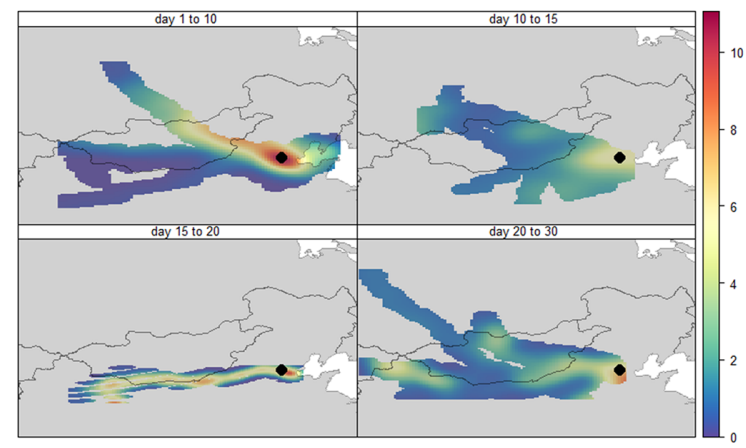

(c) Industry (pesticide)

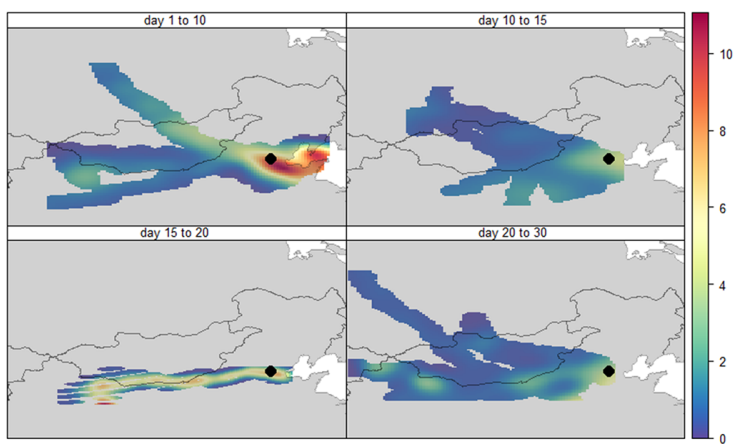

(b) Biomass burning

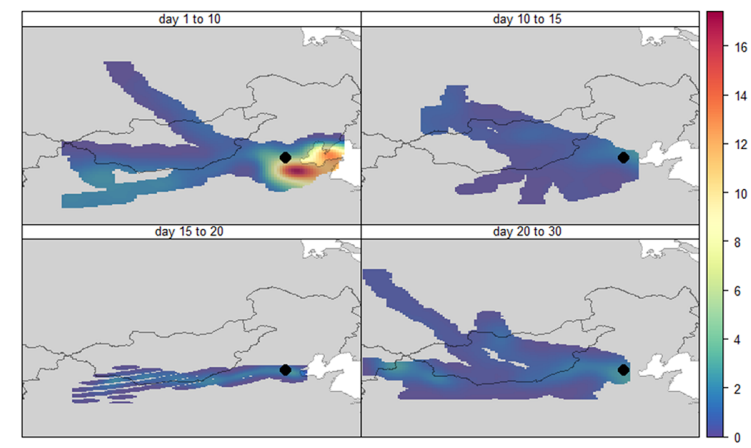

(d) Vehicle exhaust

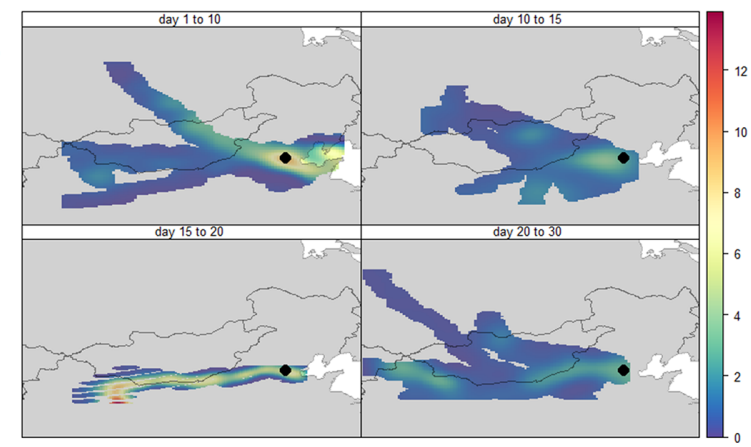

Figure 9. Concentration weighted trajectory (CWT) analysis of the sources resolved by non-negative matrix factorization (NMF), i.e., coal combustion (a), biomass burning (b), industry (c), and vehicle exhaust (d).

with $\mathrm{NO}_{2}$ and produced nitrophenol. During the non-polluted period, the reaction that produced catechol (then produced $\mathrm{NC}$ ) was the predominant phenol loss pathway by $\mathrm{OH}$ reaction $(21.9 \%)$. This stressed that the phenol- $\mathrm{C}_{6} \mathrm{H}_{5} \mathrm{O}$ pathway might play a role in the nitrophenol accumulation during the heavy pollution episode. Primary source apportionment was conducted by the NMF (KL algorithm) model with four factors. Combustion was the predominant source of primary NPs; yet $30.4 \%$ of DNP and 9.2\% of MDNP were from noncombustion sources, i.e., industry. The CWT analysis indicated a probable regional transport of combustion and the industry source from provinces that surround the Yellow and Bohai seas.

In conclusion, nitrated phenols in winter of Beijing were mainly influenced by primary emissions and regional transport; yet secondary formation could not be neglected. This study firstly stressed that primary emitted phenol rather than benzene oxidation was crucial in the rapid accumulation of NPs during the heavy pollution episode in Beijing. This result provides more insight into pollution control strategies of NPs. Both primary sources and secondary formation at either local or regional scale should be considered when making control policies of NP in North China.
Data availability. The data used in this publication can be accessed upon request to the corresponding author (songguo@pku.edu.cn).

Supplement. The supplement related to this article is available online at: https://doi.org/10.5194/acp-21-7917-2021-supplement.

Author contributions. SG designed the study. RT, SX, and HW collected the samples. KS analyzed the samples and processed the data. SG and HW constructed the paper, and KS wrote the paper, with contributions from all the coauthors.

Competing interests. The authors declare that they have no conflict of interest.

Acknowledgements. We greatly thank the reviewers for their careful review. The work was supported by the National Natural Science Foundation of China (grant nos. 51636003, 41977179, and 91844301), the National Key Research and Development Program of China (grant nos. 2016YFC0202000 and 2017YFC0213000), the Beijing Municipal Science and Technology Commission (grant no. Z201100008220011), and the Natural Science Foundation of Beijing (grant no. 8192022). 
Financial support. This research has been supported by the National Natural Science Foundation of China (grant nos. 51636003, 41977179, and 91844301), the National Key Research and Development Program of China (grant nos. 2016YFC0202000 and 2017YFC0213000), the Beijing Municipal Science and Technology Commission (grant no. Z201100008220011), and the Natural Science Foundation of Beijing (grant no. 8192022).

Review statement. This paper was edited by Alex Lee and reviewed by Thomas Mentel and one anonymous referee.

\section{References}

Bannan, T. J., Murray Booth, A., Bacak, A., Muller, J. B. A., Leather, K. E., Le Breton, M., Jones, B., Young, D., Coe, H., Allan, J., Visser, S., Slowik, J. G., Furger, M., Prévôt, A. S. H., Lee, J., Dunmore, R. E., Hopkins, J. R., Hamilton, J. F., Lewis, A. C., Whalley, L. K., Sharp, T., Stone, D., Heard, D. E., Fleming, Z. L., Leigh, R., Shallcross, D. E., and Percival, C. J.: The first UK measurements of nitryl chloride using a chemical ionization mass spectrometer in central London in the summer of 2012, and an investigation of the role of $\mathrm{Cl}$ atom oxidation, J. Geophys. Res., 120, 5638-5657, https://doi.org/10.1002/2014JD022629, 2015.

Bean, J. K. and Hildebrandt Ruiz, L.: Gas-particle partitioning and hydrolysis of organic nitrates formed from the oxidation of $\alpha$-pinene in environmental chamber experiments, Atmos. Chem. Phys., 16, 2175-2184, https://doi.org/10.5194/acp16-2175-2016, 2016.

Belloli, R., Barletta, B., Bolzacchini, E., Meinardi, S., Orlandi, M., and Rindone, B.: Determination of toxic nitrophenols in the atmosphere by high-performance liquid chromatography, J. Chromatogr. A, 846, 277-281, https://doi.org/10.1016/S00219673(99)00030-8, 1999

Berndt, T. and Böge, O.: Gas-phase reaction of $\mathrm{OH}$ radicals with phenol, Phys. Chem. Chem. Phys., 5, 342-350, https://doi.org/10.1039/b208187c, 2003.

Brunet, J. P., Tamayo, P., Golub, T. R., and Mesirov, J. P.: Metagenes and molecular pattern discovery using matrix factorization, P. Natl. Acad. Sci. USA, 101, 4164-4169, https://doi.org/10.1073/pnas.0308531101, 2004.

Cecinato, A., Di Palo, V., Pomata, D., Tomasi Scianò, M. C., and Possanzini, M.: Measurement of phase-distributed nitrophenols in Rome ambient air, Chemosphere, 59, 679-683, 2005.

Chaara, D., Pavlovic, I., Bruna, F., Ulibarri, M. A., Draoui, K., and Barriga, C.: Removal of nitrophenol pesticides from aqueous solutions by layered double hydroxides and their calcined products, Appl. Clay Sci., 50, 292-298, https://doi.org/10.1016/j.clay.2010.08.002, 2010.

Delhomme, O., Morville, S., and Millet, M.: Seasonal and diurnal variations of atmospheric concentrations of phenols and nitrophenols measured in the Strasbourg area, France, Atmos. Pollut. Res., 1, 16-22, 2010.

Devarajan, K.: Nonnegative matrix factorization: An analytical and interpretive tool in computational biology, PLoS Comput. Biol., 4, e1000029, https://doi.org/10.1371/journal.pcbi.1000029, 2008.
Fan, X. C., Lang, J. L., Cheng, S. Y., Wang, X. Q., and Lü, Z.: Seasonal Variation and Source Analysis for $\mathrm{PM}_{2.5}, \mathrm{PM}_{1}$ and Their Carbonaceous Components in Beijing, Huanjing Kexue/Environmental Sci., 39, 4430-4438, https://doi.org/10.13227/j.hjkx.201801186, 2018.

Fang, X., Hu, M., Shang, D., Tang, R., Shi, L., Olenius, T., Wang, Y., Wang, H., Zhang, Z., Chen, S., Yu, X., Zhu, W., Lou, S., Ma, Y., Li, X., Zeng, L., Wu, Z., Zheng, J., and Guo, S.: Observational Evidence for the Involvement of Dicarboxylic Acids in Particle Nucleation, Environ. Sci. Tech. Let., 7, 388394, https://doi.org/10.1021/acs.estlett.0c00270, 2020.

Fu, X., Huang, K., Sidiropoulos, N. D., and Ma, W. K.: Nonnegative Matrix Factorization for Signal and Data Analytics: Identifiability, Algorithms, and Applications, IEEE Signal Proc. Mag., 36, 59-80, https://doi.org/10.1109/MSP.2018.2877582, 2019.

Gaujoux, R. and Seoighe, C.: A flexible R package for nonnegative matrix factorization, BMC Bioinformatics, 11, 1-9, https://doi.org/10.1186/1471-2105-11-367, 2010.

Gaujoux, R. and Seoighe, C.: Using the package NMF, available at: http://cran.r-project.org/package $=\mathrm{NMF}$ (last access: 2 March 2021), 2015.

Grosjean, D. and Williams, E. L.: Environmental persistence of organic compounds estimated from structure-reactivity and linear free-energy relationships, Unsaturated aliphatics, Atmos. Environ. A-Gen., 26, 1395-1405, https://doi.org/10.1016/09601686(92)90124-4, 1992.

Guo, S., Hu, M., Guo, Q., Zhang, X., Zheng, M., Zheng, J., Chang, C. C., Schauer, J. J., and Zhang, R.: Primary sources and secondary formation of organic aerosols in Beijing, China, Environ. Sci. Technol., 46, 9846-9853, https://doi.org/10.1021/es2042564, 2012.

Guo, S., Hu, M., Zamora, M. L., Peng, J., Shang, D., Zheng, J., Du, Z., Wu, Z., Shao, M., Zeng, L., Molina, M. J., and Zhang, R.: Elucidating severe urban haze formation in China, P. Natl. Acad. Sci. USA, 111, 17373-17378, https://doi.org/10.1073/pnas.1419604111, 2014.

Guo, S., Hu, M., Peng, J., Wu, Z., Zamora, M. L., Shang, D., Du, Z., Zheng, J., Fang, X., Tang, R., Wu, Y., Zeng, L., Shuai, S., Zhang, W., Wang, Y., Ji, Y., Li, Y., Zhang, A. L., Wang, W., Zhang, F., Zhao, J., Gong, X., Wang, C., Molina, M. J., and Zhang, R.: Remarkable nucleation and growth of ultrafine particles from vehicular exhaust, P. Natl. Acad. Sci. USA, 117, $3427-$ 3432, 2020.

Harrison, M. A. J., Barra, S., Borghesi, D., Vione, D., Arsene, C., and Iulian Olariu, R.: Nitrated phenols in the atmosphere: A review, Atmos. Environ., 39, 231-248, https://doi.org/10.1016/j.atmosenv.2004.09.044, 2005.

Heberer, T. and Stan, H. J.: Detection of more than 50 substituted phenols as their t-butyldimethylsilyl derivatives using gas chromatography-mass spectrometry, Anal. Chim. Acta, 341, 21 34, https://doi.org/10.1016/S0003-2670(96)00557-0, 1997.

Huber, W., Carey, V. J., Gentleman, R., Anders, S., Carlson, M., Carvalho, B. S., Bravo, H. C., Davis, S., Gatto, L., Girke, T., Gottardo, R., Hahne, F., Hansen, K. D., Irizarry, R. A., Lawrence, M., Love, M. I., MacDonald, J., Obenchain, V., Oleś, A. K., Pagès, H., Reyes, A., Shannon, P., Smyth, G. K., Tenenbaum, D., Waldron, L., and Morgan, M.: Orchestrating high-throughput genomic analysis with Bioconductor, Nat. Methods, 12, 115-121, https://doi.org/10.1038/nmeth.3252, 2015. 
Iinuma, Y., Böge, O., and Herrmann, H.: Methyl-nitrocatechols: Atmospheric tracer compounds for biomass burning secondary organic aerosols, Environ. Sci. Technol., 44, 8453-8459, https://doi.org/10.1021/es102938a, 2010.

Inomata, S., Tanimoto, H., Fujitani, Y., Sekimoto, K., Sato, K., Fushimi, A., Yamada, H., Hori, S., Kumazawa, Y., Shimono, A., and Hikida, T.: On-line measurements of gaseous nitro-organic compounds in diesel vehicle exhaust by protontransfer-reaction mass spectrometry, Atmos. Environ., 73, 195203, https://doi.org/10.1016/j.atmosenv.2013.03.035, 2013.

Inomata, S., Fujitani, Y., Fushimi, A., Tanimoto, H., Sekimoto, K., and Yamada, H.: Field measurement of nitromethane from automotive emissions at a busy intersection using proton-transferreaction mass spectrometry, Atmos. Environ., 96, 301-309, https://doi.org/10.1016/j.atmosenv.2014.07.058, 2014.

Karl, T., Striednig, M., Graus, M., Hammerle, A., and Wohlfahrt, G.: Urban flux measurements reveal a large pool of oxygenated volatile organic compound emissions, $\mathrm{P}$. Natl. Acad. Sci. USA, 115, 1186-1191, 2018.

Laskin, A., Laskin, J., and Nizkorodov, S. A.: Chemistry of Atmospheric Brown Carbon, Chem. Rev., 115, 4335-4382, https://doi.org/10.1021/cr5006167, 2015.

Lee, D. D. and Seung, H. S.: Learning the parts of objects by non-negative matrix factorization, Nature, 401, 788-791, https://doi.org/10.1038/44565, 1999.

Lee, D. D. and Seung, H. S.: Algorithms for non-negative matrix factorization, in: 14th Annual Neural Information Processing Systems Conference, NIPS 2000, Denver, CO, United States, 27 November-2 December 2000, 2001.

Leuenberger, C., Czuczwa, J., Tremp, J., and Giger, W.: Nitrated phenols in rain: Atmospheric occurrence of phytotoxic pollutants, Pergamon, Chemosphere, 17, 511-515, 1988.

Li, K., Li, J., Tong, S., Wang, W., Huang, R.-J., and Ge, M.: Characteristics of wintertime VOCs in suburban and urban Beijing: concentrations, emission ratios, and festival effects, Atmos. Chem. Phys., 19, 8021-8036, https://doi.org/10.5194/acp19-8021-2019, 2019.

Li, Q., Lu, Y., Wang, P., Wang, T., Zhang, Y., Suriyanarayanan, S., Liang, R., Baninla, Y., and Khan, K.: Distribution, source, and risk of organochlorine pesticides (OCPs) and polychlorinated biphenyls (PCBs) in urban and rural soils around the Yellow and Bohai Seas, China, Environ. Pollut., 239, 233-241, https://doi.org/10.1016/j.envpol.2018.03.055, 2018.

Li, X., Wang, Y., Hu, M., Tan, T., Li, M., Wu, Z., Chen, S., and Tang, X.: Characterizing chemical composition and light absorption of nitroaromatic compounds in the winter of Beijing, Atmos. Environ., 237, 117712, https://doi.org/10.1016/j.atmosenv.2020.117712, 2020.

Liu, Y., Shao, M., Zhang, J., Fu, L., and Lu, S.: Distributions and source apportionment of ambient volatile organic compounds in Beijing City, China, J. Environ. Sci. Heal. A, 40, 1843-1860, 2005

Lu, C., Wang, X., Li, R., Gu, R., Zhang, Y., Li, W., Gao, R., Chen, B., Xue, L., and Wang, W.: Emissions of fine particulate nitrated phenols from residential coal combustion in China, Atmos. Environ., 203, 10-17, https://doi.org/10.1016/j.atmosenv.2019.01.047, 2019a.

Lu, C., Wang, X., Dong, S., Zhang, J., Li, J., Zhao, Y., Liang, Y., Xue, L., Xie, H., Zhang, Q., and Wang, W.:
Emissions of fine particulate nitrated phenols from various on-road vehicles in China, Environ. Res., 179, 108709, https://doi.org/10.1016/j.envres.2019.108709, 2019 b.

Lu, K., Guo, S., Tan, Z., Wang, H., Shang, D., Liu, Y., Li, X., $\mathrm{Wu}, \mathrm{Z}$., Hu, M., and Zhang, Y.: Exploring atmospheric freeradical chemistry in China: The self-cleansing capacity and the formation of secondary air pollution, Natl. Sci. Rev., 6, 579-594, https://doi.org/10.1093/nsr/nwy073, 2019.

Lüttke, J., Scheer, V., Levsen, K., Wünsch, G., Cape, J. N., Hargreaves, K. J., Storeton-West, R. L., Acker, K., Wieprecht, W., and Jones, B.: Occurrence and formation of nitrated phenols in and out of cloud, Atmos. Environ., 31, 2637-2648, 1997.

Lv, H. D., Zhou, J. S., Yang, L., Li, Y. M., and Liu, L.: An accounting of the external environmental costs of coal in Inner Mongolia using the pollution damage method, Environ. Dev. Sustain., 22 , 1299-1321, https://doi.org/10.1007/s10668-018-0249-1, 2020.

Lyu, R., Shi, Z., Alam, M. S., Wu, X., Liu, D., Vu, T. V., Stark, C., Xu, R., Fu, P., Feng, Y., and Harrison, R. M.: Alkanes and aliphatic carbonyl compounds in wintertime $\mathrm{PM}_{2.5}$ in Beijing, China, Atmos. Environ., 202, 244-255, https://doi.org/10.1016/j.atmosenv.2019.01.023, 2019.

Mohr, C., Lopez-Hilfiker, F. D., Zotter, P., Prévoît, A. S. H., Xu, L., Ng, N. L., Herndon, S. C., Williams, L. R., Franklin, J. P., Zahniser, M. S., Worsnop, D. R., Knighton, W. B., Aiken, A. C., Gorkowski, K. J., Dubey, M. K., Allan, J. D., and Thornton, J. A.: Contribution of nitrated phenols to wood burning brown carbon light absorption in detling, UK during winter time, Environ. Sci. Technol., 47, 6316-6324, https://doi.org/10.1021/es400683v, 2013.

Moreira Dos Santos, C. Y., De Almeida Azevedo, D., and De Aquino Neto, F. R.: Atmospheric distribution of organic compounds from urban areas near a coalfired power station, Atmos. Environ., 38, 1247-1257, https://doi.org/10.1016/j.atmosenv.2003.11.026, 2004.

Morville, S., Scheyer, A., Mirabel, P., and Millet, M.: Spatial and geographical variations of urban, suburban and rural atmospheric concentrations of phenols and nitrophenols, Environ. Sci. Pollut R., 13, 83-89, https://doi.org/10.1065/espr2005.06.264, 2006.

Paatero, P. and Tapper, U.: Positive matrix factorization: A non-negative factor model with optimal utilization of error estimates of data values, Environmetrics, 5, 111-126, https://doi.org/10.1002/env.3170050203, 1994.

Pascual-Montano, A., Carazo, J. M., Kochi, K., Lehmann, D., and Pascual-Marqui, R. D.: Nonsmooth nonnegative matrix factorization (nsNMF), IEEE T. Pattern Anal., 28, 403-415, https://doi.org/10.1109/TPAMI.2006.60, 2006.

Priestley, M., Le Breton, M., Bannan, T. J., Leather, K. E., Bacak, A., Reyes-Villegas, E., De Vocht, F., Shallcross, B. M. A., Brazier, T., Anwar Khan, M., Allan, J., Shallcross, D. E., Coe, H., and Percival, C. J.: Observations of Isocyanate, Amide, Nitrate, and Nitro Compounds From an Anthropogenic Biomass Burning Event Using a ToF-CIMS, J. Geophys. Res.-Atmos., 123, 76877704, https://doi.org/10.1002/2017JD027316, 2018.

Huang, Q., Wang, L., and Han, S.: The genotoxicity of substituted nitrobenzenes and the quantitative structureactivity relationship studies, Chemosphere, 30, 915-923, https://doi.org/10.1016/0045-6535(94)00450-9, 1995.

R Core Team: R Core Team 2014 R: A language and environment for statistical computing, $\mathrm{R}$ foundation for statistical 
computing, available at: http://www.r-project.org/ (last access: 2 March 2021), 2015.

Rolph, G., Stein, A., and Stunder, B.: Real-time Environmental Applications and Display sYstem: READY, Environ. Modell. Softw., 95, 210-228, https://doi.org/10.1016/j.envsoft.2017.06.025, 2017.

Ropkins, K. and Carslaw, D. C.: Openair - data analysis tools for the air quality community, R J., 4, 20-29, https://doi.org/10.32614/rj-2012-003, 2012.

Schwantes, R. H., Schilling, K. A., McVay, R. C., Lignell, H., Coggon, M. M., Zhang, X., Wennberg, P. O., and Seinfeld, J. H.: Formation of highly oxygenated low-volatility products from cresol oxidation, Atmos. Chem. Phys., 17, 3453-3474, https://doi.org/10.5194/acp-17-3453-2017, 2017.

Seibert, P., Kromp-Kolb, H., Baltensperger, U., Jost, D. T., and Schwikowski, M.: Trajectory Analysis of High-Alpine Air Pollution Data, in: Air Pollution Modeling and Its Application X, Springer, Boston, MA, USA, 595-596, 1994.

Sekimoto, K., Inomata, S., Tanimoto, H., Fushimi, A., Fujitani, Y., Sato, K., and Yamada, H.: Characterization of nitromethane emission from automotive exhaust, Atmos. Environ., 81, 523531, https://doi.org/10.1016/j.atmosenv.2013.09.031, 2013.

Shao, M., Lu, S., Liu, Y., Xie, X., Chang, C., Huang, S., and Chen, Z.: Volatile organic compounds measured in summer in Beijing and their role in ground-level ozone formation, J. Geophys. Res.-Atmos., 114, D00G06, https://doi.org/10.1029/2008JD010863, 2009.

Stark, H., Yatavelli, R. L. N., Thompson, S. L., Kimmel, J. R., Cubison, M. J., Chhabra, P. S., Canagaratna, M. R., Jayne, J. T., Worsnop, D. R., and Jimenez, J. L.: Methods to extract molecular and bulk chemical information from series of complex mass spectra with limited mass resolution, Int. J. Mass Spectrom., 389, 26-38, https://doi.org/10.1016/j.ijms.2015.08.011, 2015.

Stein, A. F., Draxler, R. R., Rolph, G. D., Stunder, B. J. B., Cohen, M. D., and Ngan, F.: Noaa's hysplit atmospheric transport and dispersion modeling system, B. Am. Meteorol. Soc., 96, 2059-2077, https://doi.org/10.1175/BAMS-D-14-00110.1, 2015.

Sunesson, A. L., Gullberg, J., and Blomquist, G.: Airborne chemical compounds on dairy farms, J. Environ. Monitor., 3, 210-216, https://doi.org/10.1039/b008873k, 2001.

Tang, R., Wu, Z., Li, X., Wang, Y., Shang, D., Xiao, Y., Li, M., Zeng, L., Wu, Z., Hallquist, M., Hu, M., and Guo, S.: Primary and secondary organic aerosols in summer 2016 in Beijing, Atmos. Chem. Phys., 18, 4055-4068, https://doi.org/10.5194/acp18-4055-2018, 2018.

Tang, R., Lu, Q., Guo, S., Wang, H., Song, K., Yu, Y., Tan, R., Liu, K., Shen, R., Chen, S., Zeng, L., Jorga, S. D., Zhang, Z., Zhang, W., Shuai, S., and Robinson, A. L.: Measurement report: Distinct emissions and volatility distribution of intermediate-volatility organic compounds from on-road Chinese gasoline vehicles: implication of high secondary organic aerosol formation potential, Atmos. Chem. Phys., 21, 2569-2583, https://doi.org/10.5194/acp21-2569-2021, 2021.

Valero-Mora, P. M.: ggplot2: Elegant Graphics for Data Analysis, J. Stat. Softw., 35, 1-3, https://doi.org/10.18637/jss.v035.b01, 2010.

Wang, X., Gu, R., Wang, L., Xu, W., Zhang, Y., Chen, B., Li, W., Xue, L., Chen, J., and Wang, W.: Emissions of fine particulate nitrated phenols from the burning of five common types of biomass, Environ. Pollut., 230, 405-412, https://doi.org/10.1016/j.envpol.2017.06.072, 2017.

Wang, Y., Hu, M., Wang, Y., Zheng, J., Shang, D., Yang, Y., Liu, Y., Li, X., Tang, R., Zhu, W., Du, Z., Wu, Y., Guo, S., Wu, Z., Lou, S., Hallquist, M., and Yu, J. Z.: The formation of nitro-aromatic compounds under high $\mathrm{NO}_{x}$ and anthropogenic VOC conditions in urban Beijing, China, Atmos. Chem. Phys., 19, 7649-7665, https://doi.org/10.5194/acp-19-7649-2019, 2019.

Wehner, B., Birmili, W., Ditas, F., Wu, Z., Hu, M., Liu, X., Mao, J., Sugimoto, N., and Wiedensohler, A.: Relationships between submicrometer particulate air pollution and air mass history in Beijing, China, 2004-2006, Atmos. Chem. Phys., 8, 6155-6168, https://doi.org/10.5194/acp-8-6155-2008, 2008.

Xie, M., Chen, X., Hays, M. D., Lewandowski, M., Offenberg, J., Kleindienst, T. E., and Holder, A. L.: Light Absorption of Secondary Organic Aerosol: Composition and Contribution of Nitroaromatic Compounds, Environ. Sci. Technol., 51, 1160711616, https://doi.org/10.1021/acs.est.7b03263, 2017.

Xu, X., Zhang, H., Chen, J., Li, Q., Wang, X., Wang, W., Zhang, Q., Xue, L., Ding, A., and Mellouki, A.: Six sources mainly contributing to the haze episodes and health risk assessment of $\mathrm{PM}_{2.5}$ at Beijing suburb in winter 2016, Ecotox. Environ. Safe., 166, 146-156, https://doi.org/10.1016/j.ecoenv.2018.09.069, 2018.

Yang, Y., Wang, Y., Zhou, P., Yao, D., Ji, D., Sun, J., Wang, Y., Zhao, S., Huang, W., Yang, S., Chen, D., Gao, W., Liu, Z., Hu, B., Zhang, R., Zeng, L., Ge, M., Petäjä, T., Kerminen, V.M., Kulmala, M., and Wang, Y.: Atmospheric reactivity and oxidation capacity during summer at a suburban site between Beijing and Tianjin, Atmos. Chem. Phys., 20, 8181-8200, https://doi.org/10.5194/acp-20-8181-2020, 2020.

Yatavelli, R. L. N., Lopez-Hilfiker, F., Wargo, J. D., Kimmel, J. R., Cubison, M. J., Bertram, T. H., Jimenez, J. L., Gonin, M., Worsnop, D. R., and Thornton, J. A.: A chemical ionization highresolution time-of-flight mass spectrometer coupled to a micro orifice volatilization impactor (MOVI-HRToF-CIMS) for analysis of gas and particle-phase organic species, Aerosol Sci. Tech., 46, 1313-1327, https://doi.org/10.1080/02786826.2012.712236, 2012.

Yatavelli, R. L. N., Stark, H., Thompson, S. L., Kimmel, J. R., Cubison, M. J., Day, D. A., Campuzano-Jost, P., Palm, B. B., Hodzic, A., Thornton, J. A., Jayne, J. T., Worsnop, D. R., and Jimenez, J. L.: Semicontinuous measurements of gas-particle partitioning of organic acids in a ponderosa pine forest using a MOVI-HRToF-CIMS, Atmos. Chem. Phys., 14, 1527-1546, https://doi.org/10.5194/acp-14-1527-2014, 2014.

Yu, Y., Wang, H., Wang, T., Song, K., Tan, T., Wan, Z., Gao, Y., Dong, H., Chen, S., Zeng, L., Hu, M., Wang, H., Lou, S., Zhu, W., and Guo, S.: Elucidating the importance of semi-volatile organic compounds to secondary organic aerosol formation at a regional site during the EXPLORE-YRD campaign, Atmos. Environ., 246, 118043 , https://doi.org/10.1016/j.atmosenv.2020.118043, 2021.

Yuan, B., Hu, W. W., Shao, M., Wang, M., Chen, W. T., Lu, S. H., Zeng, L. M., and Hu, M.: VOC emissions, evolutions and contributions to SOA formation at a receptor site in eastern China, Atmos. Chem. Phys., 13, 8815-8832, https://doi.org/10.5194/acp13-8815-2013, 2013. 
Yuan, B., Liggio, J., Wentzell, J., Li, S.-M., Stark, H., Roberts, J. M., Gilman, J., Lerner, B., Warneke, C., Li, R., Leithead, A., Osthoff, H. D., Wild, R., Brown, S. S., and de Gouw, J. A.: Secondary formation of nitrated phenols: insights from observations during the Uintah Basin Winter Ozone Study (UBWOS) 2014, Atmos. Chem. Phys., 16, 2139-2153, https://doi.org/10.5194/acp-16-2139-2016, 2016.

Zheng, J., Ma, Y., Chen, M., Zhang, Q., Wang, L., Khalizov, A. F., Yao, L., Wang, Z., Wang, X., and Chen, L.: Measurement of atmospheric amines and ammonia using the high resolution time-of-flight chemical ionization mass spectrometry, Atmos. Environ., 102, 249-259, https://doi.org/10.1016/j.atmosenv.2014.12.002, 2015.
Zhu, J., Newhook, R., Marro, L., and Chan, C. C.: Selected volatile organic compounds in residential air in the city of Ottawa, Canada, Environ. Sci. Technol., 39, 3964-3971, https://doi.org/10.1021/es050173u, 2005. 